\title{
Fatores que interferem no aleitamento materno: Implicações para enfermagem
}

\author{
Factors that interfer in breastfeeding: Implications for nursing \\ Factores que interfieren em la lactancia: Implicaciones para la enfermería
}

Camila Gomes Zardo $^{1}$, Camila Berto Fernandes Rangel ${ }^{2}$, Diogo Jacintho Barbosa ${ }^{3 *}$

Como citar esse artigo. Zardo, CG; Rangel, CBF; Barbosa, DJ. Fatores que interferem no aleitamento materno: Implicações para enfermagem. Revista Pró-UniverSUS. 2020 Jul./Dez.; 11 (2): 129-140.

\section{Resumo}

Objetivo: Identificar os fatores que interferem no aleitamento materno e as implicações para a prática de enfermagem. Metodologia: método com conjunto das atividades sistemáticas e racionais que, com maior segurança e economia, permite alcançar o objetivo - conhecimentos válidos e verdadeiros -, traçando o caminho a ser seguido, detectando erros e auxiliando as decisões do cientista. Foi realizado um levantamento de dados através da base de dados Biblioteca Virtual em Saúde, com artigos publicados no período de 2014 a 2019. Resultados: Foram encontrados 622 artigos, a amostra final desta revisão foi constituída por 28 artigos científicos, selecionados pelos critérios de inclusão previamente estabelecidos. Conclusão: Apesar das limitações encontradas no presente estudo a pratica de amamanetação tem se mostrado eficaz pelas puerpéras, contudo é um trabalho que deve ser desempenhado pela enfermagem de forma efetiva, auxiliando nas dificuldades encontradas e ressaltando a importância do aleitameno materno.

Palavras-chave: Aleitamento materno; Enfermagem; Gestação.

\begin{abstract}
Objective: To identify the factors that interfere with breastfeeding and the implications for nursing practice. Methodology: method with a set of systematic and rational activities that, with greater security and economy, allows reaching the goal valid and true knowledge -, tracing the path to be followed, detecting errors and helping scientist's decisions. A data survey was carried out through the Virtual Health Library database, with articles published from 2014 to 2019. Results: 622 articles were found, the final sample of this review was made up of 28 scientific articles, selected by the inclusion criteria previously established. Conclusion: Despite the limitations found in the present study, the practice of breastfeeding has been shown to be effective by the puerperal women, however it is a job that should be performed by nursing effectively, helping with the difficulties encountered and emphasizing the importance of breastfeeding.
\end{abstract}

Keywords: Breastfeeding; Nursing; Gestation.

\section{Resumen}

Objetivo: Identificar los factores que interfieren con la lactancia materna y las implicaciones para la práctica de enfermería. Metodología: método con un conjunto de actividades sistemáticas y racionales que, con mayor seguridad y economía, permite alcanzar la meta -conocimiento válido y verdadero-, trazar el camino a seguir, detectar errores y ayudar decisiones de los científicos. Se realizó una encuesta de datos a través de la base de datos de la Biblioteca Virtual en Salud, con artículos publicados de 2014 a 2019. Resultados: se encontraron 622 artículos, la muestra final de esta revisión estuvo conformada por 28 artículos científicos, seleccionados por los criterios de inclusión establecido previamente. Conclusión: A pesar de las limitaciones encontradas en el presente estudio, la práctica de la lactancia materna ha demostrado ser efectiva por parte de las puérperas, sin embargo es un trabajo que debe realizar la enfermería de manera efectiva, ayudando con las dificultades encontradas y enfatizando la importancia de la lactancia materna.

Palabras clave: Amamantamiento; Enfermería; Gestación.

Afiliação dos autores:

${ }^{1}$ Acadêmica de Enfermagem da Faculdade Gama e Souza. RJ, Brasil. ORCID: https://orcid.org/0000-0001-8744-4189

${ }^{2}$ Acadêmica de Enfermagem da Faculdade Gama e Souza. RJ, Brasil. ORCID: https://orcid.org/0000-0001-9226-9135

${ }^{3}$ Professor Substituto da Universidade Federal do Rio de Janeiro-UFRJ. Docente do Curso de Enfermagem da Faculdade Gama e Souza. Doutorando em Enfermagem na Faculdade

de Enfermagem da UERJ. RJ. Brasil. ORCID: https://orcid.org/0000-0001-6171-0768 


\section{Introdução}

O aleitamento materno (AM) sempre esteve e sempre estará presente na vida das mulheres e seus filhos, essa prática consiste em conceder a criança o leite materno que é produzido pela mulher e contém todos os tipos de nutrientes como vitaminas, proteínas, carboidratos, lipídios, sais minerais e água que é necessário para o seu crescimento e desenvolvimento. O AM é o método mais recomendado e eficaz na alimentação do bebê, sendo a fonte ideal de nutrição para a criança.

A Organização Pan-Americana da Saúde/ Organização Mundial da Saúde recomenda iniciar a amamentação nos primeiros 60 minutos de vida, assim como o aleitamento materno como forma exclusiva de alimentação até os seis meses de idade e, de maneira complementar, até os dois anos. ${ }^{1}$

A prática do AM além de reduzir a mortalidade infantil, traz diversos benefícios tanto para o lactante quanto para a nutriz, a começar pelo lactante é um alimento completo, de fácil digestão, estimula o desenvolvimento da musculatura e ossatura bucal e protege o lactente de desenvolver doenças respiratórias, infecções, diarreias, reduz o risco de doenças crônicas como diabete de mellitus, celíaca, autoimune, alergia alimentar, entre outras. Para a nutriz, reduz o risco de desenvolver fraturas ósseas, câncer de mama e de ovários, de acordo com estudos diminui o risco de morte por artrite reumatoide, além de diminuir o custo e o mais importante aumenta o vínculo mãe-filho. ${ }^{2}$

Os benefícios da amamentação não atingem somente a fase da infância, mas também a fase adulta, estando relacionada à diminuição do desenvolvimento de doenças cardiovasculares, surgimento de diabetes, risco de desenvolver câncer e risco de disfunção neurológica. ${ }^{2}$

O enfermeiro é o profissional mais próximo ao período do puerpério, pois exerce funções de ensinar as mães, tirar as dúvidas que irão surgir, falar sobre os pontos positivos e negativos da gestação. É de grande importância a enfermagem fazer educação em saúde, palestras e ações sociais com as gestantes frente a gestação, amamentação, cuidados com o bebê e com si mesma, sendo abordado um assunto de cada vez para não gerar incertezas e assim esclarecendo dúvidas necessárias sobre os benefícios da amamentação para a qualidade de vida da mãe e do filho.

Nosso grande afeto pelas áreas obstétrica, pediátrica e saúde da mulher nos levou a pensar sobre o aleitamento materno. Como também a crescente de familiares e amigas que tiveram/ terão filhos e a falta de informação que lhes é dada sobre a importância e o que interfere o aleitamento materno, a introdução de alimentos complementares antes de completar os seis meses de leite materno exclusivo como também o desmame precoce, onde ambos prejudicam o crescimento e desenvolvimento da criança.

Sendo assim um estudo relevante, pois tem se tornado cada vez mais comum e importante para a sociedade a conscientização quanto a importância do aleitamento materno. Além de existir ainda dúvidas sobre o assunto, onde os profissionais não estão preparados para educar corretamente as mães. É de grande importância para a enfermagem onde irá melhorar a abordagem dos enfermeiros frente ao AM e para nós acadêmicos irá contribuir no enriquecimento do assunto já que ainda existem dúvidas.

A partir destas premissas foi possível construir a pergunta de pesquisa, a saber: quais são os fatores que interferem no aleitamento materno e quais as implicações para a enfermagem? Para responder esta pergunta traçamos como objetivo geral do estudo: Identificar os fatores que interferem no aleitamento materno e como objetivos específicos analisar os fatores que interferem no aleitamento materno e as implicações para a prática de enfermagem.

\section{Material e Método}

Ao ensinar sua metodologia, vem demonstrando de forma lúcida e clara métodos e conceitos para melhor formulação de uma pesquisa, tanto no aspecto prático e visual, como também na forma de observação, descrição, análise e conclusão de eventos, através da conceituação e exemplificação de métodos, fatos, leis e hipóteses. Assim, o método é o conjunto das atividades sistemáticas e racionais que, com maior segurança e economia, permite alcançar o objetivo - conhecimentos válidos e verdadeiros -, traçando o caminho a ser seguido, detectando erros e auxiliando as decisões do cientista. $^{3}$

“... É sistemático, já que se trata de um saber ordenado
logicamente, formando um sistema de ideias (teoria)
e não conhecimentos dispersos e desconexos. Possui
a característica da verificabilidade, a tal ponto que as
afirmações (hipóteses) que não podem ser comprovadas
não pertencem ao âmbito da ciência. Constitui-se em
conhecimento falível, em virtude de não ser definitivo,
absoluto ou final e, por este motivo, é aproximadamente
exato: novas proposições e o desenvolvimento de
técnicas podem reformular o acervo de teoria existente"3

Para a realização desta análise, utilizaremos como base a Biblioteca Virtual em Saúde, serão utilizadas as seguintes palavras chave: "enfermagem"; "gestação"; "aleitamento materno". Os critérios de inclusão baseiam-se em artigos completos disponíveis de maneira gratuita, no idioma português e que foram publicados de 2014 a 2019. A análise qualitativa se deu por leitura previa das obras na parte quantitativa, foi 
feito quadro com síntese das obras para elaboração das categorias por aproximação de conteúdo.

\section{Resultados}

A busca na base de dados retornou 622 artigos, após a aplicação dos filtros, encontramos 57 artigos, estes foram selecionados para leitura o que resultou em uma amostra final de 27 artigos. A tabela 1 demonstra os artigos que compõem a amostra final deste estudo.

Observa-se que há uma gama maior de artigos publicados no ano de 2018 (10), seguido de 2015 (6), 2017 (4), 2014 e 2019 (3) e por fim, 2016 (1).

Referente as revistas, temos como maior revista publicadora a Rev. enferm. UFPE on line (8), seguida da Esc. Anna Nery Rev. Enferm (5), Rev. pesqui. cuid. fundam. (Online) (4), Nursing (Säo Paulo), REME rev. min. enferm (2) e o restante ambos com (1) publicação. Sendo grande maioria revistas de enfermagem, exceto Rev. bras. promoç. saúde (Impr.). Brasil.

Todas os artigos têm como país de origem o

O tipo de pesquisa mais utilizado de forma decrescente é o descritivo, qualitativo, exploratório, quantitativo, transversal, intervencionista, fenomenológico, de campo, controlado, randomizado e teórico-reflexivo.

\section{Sentimentos das mães soropositivas HIV e a importância da enfermagem frente a não amamentação}

O Vírus da Imunodeficiência Adquirida (HIV) causa a destruição progressiva do sistema imunológico, fazendo com que esse não consiga combater as infecções e doenças. Surgem-se, assim, as chamadas "infecções oportunistas", que são infecções que se aproveitam da fragilidade do organismo; já a Síndrome de Imunodeficiência Adquirida (AIDS) refere-se às etapas mais avançadas da infecção pelo HIV, ou seja, é quando ocorre mais de 20 infecções oportunistas ou cânceres relacionados ao vírus. Continua frisando que, notificaram-se no Brasil, entre 2000 e 2017, 108.134 gestantes infectadas, o que reflete uma situação de alerta e requer cuidados específicos. Ocorrem-se, aproximadamente, $65 \%$ da transmissão vertical (TV) durante o trabalho de parto ou no próprio parto; 35\% ocorrem em ambiente intrauterino, com frequência nas últimas semanas de gestação, sendo que a taxa de TV durante a amamentação fica entre $7 \%$ a $22 \%$, renovandose a cada exposição. ${ }^{4}$

O programa DST/Aids recomenda a utilização da terapia antirretroviral durante o período do ciclo gravídico-puerperal, sobretudo para o recém-nascido. Desse modo, a Organização Mundial da Saúde adverte que as mulheres soropositivas para o HIV não devem amamentar os seus filhos, mesmo com comprovação de antirretrovirais durante o período de gestação, parto e pós-parto. Assim, o aleitamento materno permanece contraindicado sendo, então, realizada a inibição da lactação logo após o parto, constituindo essa uma das recomendações do Ministério da Saúde. ${ }^{5}$

Pode-se conseguir a inibição da lactação logo após o parto, com medidas mecânicas e farmacológicas. Versam-se as medidas mecânicas em realizar a compressão das mamas (enfaixamento), pois essa medida, isoladamente, obtém sucesso em até $80 \%$ dos casos, quando mantida pelo período de sete a dez dias. Deve-se, porém, evitar a manipulação e estimulação das mamas e, em casos de dificuldades de programar essa medida, pode-se adotar a supressão farmacológica com a utilização do inibidor de lactação. ${ }^{4}$

Os autores prosseguem relatando seus casos de estudo que as mulheres se sentiram desesperadas, no

Tabela 1. Apresentação dos artigos que compõem a amostra final do estudo.

\begin{tabular}{|c|c|c|c|c|c|}
\hline AUTOR & TÍTULO & REVISTA & ANO & TIPO DE PESQUISA & PAIS \\
\hline $\begin{array}{c}\text { MÓTA, J. L.S. } \\
\text { et al. }\end{array}$ & $\begin{array}{c}\text { Sala de apoio à amamentação na univer- } \\
\text { sidade }\end{array}$ & $\begin{array}{c}\text { Rev. enferm. } \\
\text { UFPE on line }\end{array}$ & 2019 & Estudo descritivo \\
\hline $\begin{array}{c}\text { LIMA, C. N. } \\
\text { et al. }\end{array}$ & $\begin{array}{c}\text { Aleitamento materno: a visão de puér- } \\
\text { peras soropositivas para HIV e HTLV } \\
\text { quanto a não amamentação }\end{array}$ & $\begin{array}{c}\text { Nursing (Säo } \\
\text { Paulo) }\end{array}$ & 2019 & $\begin{array}{c}\text { Estudo descritivo com aborda- } \\
\text { gem qualitativa. }\end{array}$ & Brasil \\
\hline $\begin{array}{c}\text { SOUZA, F. L. } \\
\text { P. De. Et al }\end{array}$ & $\begin{array}{c}\text { Sentimentos e significados: HIV na im- } \\
\text { possibilidade de amamentar }\end{array}$ & $\begin{array}{c}\text { Rev. enferm. } \\
\text { UFPE on line }\end{array}$ & 2019 & $\begin{array}{c}\text { Estudo qualitativo, descritivo, } \\
\text { exploratório e fenomenológico }\end{array}$ & Brasil \\
\hline $\begin{array}{c}\text { FASSARELLA, } \\
\text { B. P. A. et al }\end{array}$ & $\begin{array}{c}\text { Percepção da equipe de enfermagem } \\
\text { frente ao aleitamento materno: do conhe- } \\
\text { cimento à implementação }\end{array}$ & $\begin{array}{c}\text { Nursing (Säo } \\
\text { Paulo) }\end{array}$ & 2018 & $\begin{array}{c}\text { Estudo qualitativa de aborda- } \\
\text { gem descritiva }\end{array}$ & Brasil \\
\hline $\begin{array}{c}\text { THULER, A. } \\
\text { C. De. M. C. } \\
\text { et al. }\end{array}$ & $\begin{array}{c}\text { Caracterização das mulheres no ciclo } \\
\text { gravídico - puerperal e o incentivo a } \\
\text { amamentação precoce }\end{array}$ & $\begin{array}{c}\text { Rev. enferm. } \\
\text { UERJ }\end{array}$ & 2018 & $\begin{array}{c}\text { Estudo quantitativo, descritivo, } \\
\text { longitudinal }\end{array}$ & Brasil \\
\hline
\end{tabular}


Tabela 1 (cont.). Apresentação dos artigos que compõem a amostra final do estudo

\begin{tabular}{|c|c|c|c|c|c|}
\hline AUTOR & TÍTULO & REVISTA & ANO & TIPO DE PESQUISA & PAIS \\
\hline $\begin{array}{l}\text { SILVA, A. M. } \\
\text { Da. et al }\end{array}$ & $\begin{array}{l}\text { Aleitamento materno exclusivo: empeci- } \\
\text { lhos apresentados por primíparas }\end{array}$ & $\begin{array}{l}\text { Rev. enferm. } \\
\text { UFPE on line }\end{array}$ & 2018 & $\begin{array}{l}\text { Estudo quantitativo, de campo, } \\
\text { exploratório e descritivo }\end{array}$ & Brasil \\
\hline $\begin{array}{l}\text { ROCHA, F. N. } \\
\text { P. Da. S. et al }\end{array}$ & $\begin{array}{l}\text { Caracterização do conhecimento das puér- } \\
\text { peras acerca do aleitamento materno }\end{array}$ & $\begin{array}{l}\text { Rev. enferm. } \\
\text { UFPE on line }\end{array}$ & 2018 & Estudo quantitativo, transversal & Brasil \\
\hline $\begin{array}{l}\text { GARCIA, E. S. } \\
\text { G. F. et al }\end{array}$ & $\begin{array}{l}\text { As ações de enfermagem no cuidado à } \\
\text { gestante: um desafio à atenção primária } \\
\text { de saúde }\end{array}$ & $\begin{array}{l}\text { Rev. pesqui. cuid. } \\
\text { fundam. (Online) }\end{array}$ & 2018 & Estudo descritivo e transversal & Brasil \\
\hline $\begin{array}{l}\text { GUIMARÃES, } \\
\text { C. M. De. S. } \\
\text { et al }\end{array}$ & $\begin{array}{l}\text { A autoeficácia na amamentação e a prática } \\
\text { profissional do enfermeiro }\end{array}$ & $\begin{array}{l}\text { Rev. enferm. } \\
\text { UFPE on line }\end{array}$ & 2018 & Estudo qualitativo e descritivo & Brasil \\
\hline $\begin{array}{l}\text { COSTA, E. F. } \\
\text { G. Da. et al }\end{array}$ & $\begin{array}{l}\text { Atuação do enfermeiro no manejo clínico } \\
\text { da amamentação: estratégias para o aleita- } \\
\text { mento materno }\end{array}$ & $\begin{array}{l}\text { Rev. pesqui. cuid. } \\
\text { fundam. (Online) }\end{array}$ & 2018 & $\begin{array}{l}\text { Estudo descritivo - exploratório } \\
\text { de natureza qualitativa }\end{array}$ & Brasil \\
\hline $\begin{array}{l}\text { SILVA, D. D. } \\
\text { Da. Et al }\end{array}$ & $\begin{array}{l}\text { Promoção do aleitamento materno no } \\
\text { pré-natal: discurso das gestantes e dos } \\
\text { profissionais da saúde }\end{array}$ & $\begin{array}{l}\text { REME rev. min. } \\
\text { enferm }\end{array}$ & 2018 & $\begin{array}{l}\text { Estudo qualitativo, exploratório } \\
\text { - descritivo }\end{array}$ & Brasil \\
\hline $\begin{array}{l}\text { TROJANH, T. } \\
\text { C. et al }\end{array}$ & $\begin{array}{l}\text { Cuidado de enfermagem as mães de } \\
\text { recém-nascidos pré-termo para manuten- } \\
\text { ção da lactação: estudo fenomenológico }\end{array}$ & $\begin{array}{l}\text { REME rev. min. } \\
\text { enferm }\end{array}$ & 2018 & $\begin{array}{l}\text { Estudo com abordagem fenome- } \\
\text { nológica }\end{array}$ & Brasil \\
\hline $\begin{array}{l}\text { JAVORSKI, M. } \\
\quad \text { et al. }\end{array}$ & $\begin{array}{l}\text { Efeitos de uma tecnologia educativa na } \\
\text { autoeficácia para amamentar e na prática } \\
\text { do aleitamento materno exclusivo }\end{array}$ & $\begin{array}{l}\text { Rev. Esc. En- } \\
\text { ferm. USP }\end{array}$ & 2018 & $\begin{array}{l}\text { Estudo de intervenção, controla- } \\
\text { do e randomizado }\end{array}$ & Brasil \\
\hline $\begin{array}{l}\text { VIEIRA, G. M. } \\
\text { et al. }\end{array}$ & $\begin{array}{l}\text { Protocolo de enfermagem para assistência } \\
\text { a mulher em processo de lactação }\end{array}$ & $\begin{array}{l}\text { Rev. pesqui. cuid. } \\
\text { fundam. (Online) }\end{array}$ & 2017 & Estudo descritivo & Brasil \\
\hline $\begin{array}{l}\text { SANTOS, R. P. } \\
\text { B. et al }\end{array}$ & $\begin{array}{l}\text { Importância do colostro para saúde do } \\
\text { recém-nascido: percepção das puérperas }\end{array}$ & $\begin{array}{l}\text { Rev. enferm. } \\
\text { UFPE on line }\end{array}$ & 2017 & $\begin{array}{c}\text { Estudo exploratório, descritivo e } \\
\text { intervencionista, de abordagem } \\
\text { qualitativa }\end{array}$ & Brasil \\
\hline $\begin{array}{l}\text { TEIXEIRA, M. } \\
\text { A. et al }\end{array}$ & $\begin{array}{c}\text { Cuidar em enfermagem às famílias que } \\
\text { vivencia a amamentação }\end{array}$ & $\begin{array}{l}\text { Rev. enferm. } \\
\text { UFPE on line }\end{array}$ & 2017 & $\begin{array}{l}\text { Estudo qualitativo e interven- } \\
\text { cionista }\end{array}$ & Brasil \\
\hline $\begin{array}{l}\text { SILVA, E. De. } \\
\text { C. et al }\end{array}$ & $\begin{array}{l}\text { Puerpério e assistência de enfermagem: } \\
\text { percepção das mulheres }\end{array}$ & $\begin{array}{l}\text { Rev. enferm. } \\
\text { UFPE on line }\end{array}$ & 2017 & $\begin{array}{l}\text { Estudo exploratório de aborda- } \\
\text { gem qualitativo }\end{array}$ & Brasil \\
\hline $\begin{array}{l}\text { LEITE, G. De. } \\
\text { O. et al }\end{array}$ & $\begin{array}{l}\text { Representações sociais de mulheres sobre } \\
\text { o cheiro do leite materno }\end{array}$ & $\begin{array}{l}\text { Esc. Anna Nery } \\
\text { Rev. Enferm }\end{array}$ & 2016 & Estudo qualitativo & Brasil \\
\hline $\begin{array}{l}\text { AZEVEDO, A. } \\
\text { R. R. et al }\end{array}$ & $\begin{array}{l}\text { O manejo clínico da amamentação: sabe- } \\
\text { res dos enfermeiros }\end{array}$ & $\begin{array}{l}\text { Esc. Anna Nery } \\
\text { Rev. Enferm }\end{array}$ & 2015 & $\begin{array}{c}\text { Estudo descritivo, exploratório e } \\
\text { qualitativo }\end{array}$ & Brasil \\
\hline $\begin{array}{l}\text { COSTA, A. M. } \\
\text { S. Da. Et al }\end{array}$ & $\begin{array}{l}\text { Cuidado de enfermagem às puérperas } \\
\text { soropositivas para o HIV diante da impos- } \\
\text { sibilidade de amamentação natural }\end{array}$ & $\begin{array}{l}\text { Rev. pesqui. cuid. } \\
\text { fundam. (Online) }\end{array}$ & 2015 & $\begin{array}{l}\text { Estudo descritivo, exploratório, } \\
\text { de natureza qualitativa }\end{array}$ & Brasil \\
\hline $\begin{array}{l}\text { PRATES, L. A. } \\
\text { et al }\end{array}$ & $\begin{array}{l}\text { Rede de apoio social de puérperas na } \\
\text { prática da amamentação }\end{array}$ & $\begin{array}{l}\text { Esc. Anna Nery } \\
\text { Rev. Enferm }\end{array}$ & 2015 & $\begin{array}{l}\text { Estudo qualitativo do tipo } \\
\text { descritivo }\end{array}$ & Brasil \\
\hline $\begin{array}{l}\text { ANDRADE, R. } \\
\text { D. et al }\end{array}$ & $\begin{array}{l}\text { Fatores relacionados à saúde da mulher } \\
\text { no puerpério e repercussões na saúde da } \\
\text { criança } \\
\end{array}$ & $\begin{array}{l}\text { Esc. Anna Nery } \\
\text { Rev. Enferm }\end{array}$ & 2015 & Estudo teórico-reflexivo & Brasil \\
\hline $\begin{array}{l}\text { LOPES, A. M. } \\
\text { et al }\end{array}$ & $\begin{array}{c}\text { Amamentação em prematuros: caracteri- } \\
\text { zação do binômio mãe-filho e autoeficácia } \\
\text { materna }\end{array}$ & $\begin{array}{l}\text { Rev. bras. } \\
\text { promoç. saúde } \\
\text { (Impr.) }\end{array}$ & 2015 & $\begin{array}{l}\text { Estudo do tipo transversal, } \\
\text { descritivo, exploratório, com } \\
\text { abordagem quantitativa }\end{array}$ & Brasil \\
\hline $\begin{array}{l}\text { TELES, G. M. } \\
\text { et al }\end{array}$ & $\begin{array}{l}\text { Amamentação no período de transição } \\
\text { neonatal em hospital amigo da criança }\end{array}$ & $\begin{array}{l}\text { Rev. eletrônica } \\
\text { enferm }\end{array}$ & 2015 & $\begin{array}{l}\text { Estudo quantitativo, explorató- } \\
\text { rio, do tipo transversal }\end{array}$ & Brasil \\
\hline $\begin{array}{l}\text { MAZZA, V. } \\
\text { De. A. et al }\end{array}$ & $\begin{array}{l}\text { Influência das redes sociais de apoio para } \\
\text { nutrizes adolescentes no processo de } \\
\text { amamentação }\end{array}$ & Cogitare enferm & 2014 & $\begin{array}{l}\text { Estudo exploratório de aborda- } \\
\text { gem qualitativa }\end{array}$ & Brasil \\
\hline $\begin{array}{l}\text { D'ARTIBALE, } \\
\text { E. F. et al }\end{array}$ & $\begin{array}{l}\text { A prática do quarto passo da iniciativa do } \\
\text { hospital amigo da criança }\end{array}$ & $\begin{array}{l}\text { Esc. Anna Nery } \\
\text { Rev. Enferm }\end{array}$ & 2014 & $\begin{array}{l}\text { Estudo descritivo, exploratório, } \\
\text { com abordagem qualitativo }\end{array}$ & Brasil \\
\hline $\begin{array}{l}\text { MAEDA, T. } \\
\text { De. C. et al }\end{array}$ & $\begin{array}{l}\text { Importância atribuída por puérperas às } \\
\text { atividades desenvolvidas no pré-natal }\end{array}$ & $\begin{array}{l}\text { Rev. enferm. } \\
\text { atenção saúde }\end{array}$ & 2014 & $\begin{array}{l}\text { Estudo descritivo, transversal } \\
\text { com abordagem quantitativa }\end{array}$ & Brasil \\
\hline
\end{tabular}

Fonte: Pesquisa dos autores 
momento da descoberta do diagnóstico, em pânico, pois elas não aceitaram os sintomas e as possibilidades de tratamento. Refletiu-se sobre casos de pessoas que morreram no sofrimento da Aids. Pensou-se nos filhos/as e em como eles ficariam sozinhos caso elas morressem. Evidenciaram-se sentimento de tristeza, medo e frustração e, apesar disso, elas fazem de tudo para cuidar e proteger os filhos da condição de saúde. Percebe-se também que há pessoas que, quando sabem que elas têm a doença, se afastam e, assim, preferem manter sigilo quanto ao diagnóstico. Demonstrase também que embora as mães soubessem que não podiam amamentar devido às orientações recebidas, todas apresentaram, em um primeiro momento do diagnóstico, pouco conhecimento acerca do tratamento, externando informações superficiais ou equivocadas; no entanto, à medida que foram convivendo com o tratamento, sentiram-se mais seguras porque entenderam a funcionalidade dos medicamentos. ${ }^{4}$

É competência da enfermagem o auxílio no binômio mãe-filho visando reconhecer eventuais dificuldades apresentadas pela mãe para relacionarse com seu filho, de modo que as recomendações realizadas reduzam o risco de transmissão vertical, sejam cumpridas e colaborem com a criação do vínculo mãe e bebê. Evitando assim, que essas mães desenvolvam sentimentos relacionados a não amamentação além da tristeza como a culpa, frustação, angústia e impotência, desejando que não fosse soropositiva e para que seu filho possa crescer de forma saudável. ${ }^{6}$

Costa et. al ainda ressalta que desse modo, o aconselhamento deve promover uma escuta sensível da mulher, uma interação enfermeiro-mulher, a fim de contribuir com as informações a respeito da sua impossibilidade de amamentar, e compreendê-la como sujeito do processo. Essa interação deve ser estimulada em todo momento, na admissão, na assistência e na alta hospitalar, para contribuir com o entendimento da mulher acerca dessas questões e preservar a saúde e o bem-estar da criança. ${ }^{5}$

\section{Suporteàs lactantes, fatores edesconfortos que prejudicam a amamentação precoce}

O ato de amamentar é de grande relevância, pois, não sendo apenas uma prática instintiva, se refere a uma necessidade, e é importante que haja o entendimento para que ocorra a sua continuidade em ambiente específico e propício. $^{7}$

A começar pela rede de apoio as lactantes, a necessidade do amparo de empresas, bem como de universidades, para que as nutrizes consigam desempenhar a recomendação da OMS, de amamentar exclusivamente até os seis meses, podendo perdurar o aleitamento até dois anos ou mais. Acredita-se que esse apoio acontece por meio de salas de apoio à amamentação ou de espaços que possam contribuir para esse ato.?

Aponta ainda que a carga horária excessiva de atividades acadêmicas e a escassez de um ambiente adequado para a realização do aleitamento materno na universidade comoas principais dificuldades encontradas pelas mães universitárias no processo de amamentação e mostra que em relação às funcionárias, por estudos, que mais da metade das mulheres que trabalham tem, como consequência, a interrupção da amamentação, e tal fato confirma a importância da existência de estratégias de apoio a essas mulheres, em seu local de trabalho, visando à continuidade do aleitamento materno. Acredita-se que a oferta de flexibilidade de horários e a promoção das estratégias de apoio, como a licença maternidade, já alcançadas, são, de fato, cruciais, entretanto, o apoio institucional quanto à implementação de salas de apoio ao aleitamento materno tem maior influência no êxito desse processo, proporcionando um maior vínculo entre o binômio mãe-filho. Consideram-se tais fatores cruciais, uma vez que a ausência do apoio, seja ele familiar ou profissional, acarreta uma probabilidade maior de ocorrer a introdução de leite industrializado e da inserção de alimentação complementar, contribuindo para a interrupção precoce do aleitamento materno. ${ }^{7}$

$\mathrm{O}$ apoio ao aleitamento materno deve ser iniciado durante o pré-natal, para que as dificuldades sejam reconhecidas e superadas. Segundo o MS, as orientações durante as consultas devem informar as vantagens da amamentação, promover a autoconfiança e habilidade, mediante o ensinamento das técnicas de posicionamento e pega correta. ${ }^{8}$

$\mathrm{Na}$ rede de apoio social as mulheres lactantes e que com exceção de quatro puérperas, as demais não mencionaram, em suas falas, o profissional de saúde como alguém que fazia parte de sua rede de apoio social na prática da amamentação. Entre os variados motivos atrelados, acredita-se que as participantes percebem os profissionais de saúde apenas como fontes de informação e não de apoio e, portanto, estes não são considerados como pertencentes às suas redes de apoio social. Sendo assim, na ocorrência de intercorrências ou dúvidas referentes à amamentação, elas buscam indivíduos que possam thes fornecer apoio, como os familiares (mãe, avós, sogras, irmãs) e outras pessoas (vizinhas e amigas) significativas de sua rede de apoio social. Em relação aos familiares, principalmente às avós, há de se considerar que sua influência pode favorecer ou dificultar o ato de amamentar, pois ao transmitir sua experiência, ela, também, transmite crenças, mitos e tradições enraizados no contexto familiar, os quais, muitas vezes, não possuem comprovação científica e diferem das recomendações atuais. Portanto, é preciso destacar que algumas avós provêm de uma geração que desvalorizava o leite materno e não o considerava como 
a única fonte de alimento para a criança. Sendo assim, mesmo com boas intenções, algumas vezes, elas podem repassar orientações errôneas, que podem contribuir para o desmame precoce. ${ }^{9}$

Entretanto, há de se considerar que, em alguns casos, as avós, assim como as mães das puérperas e suas sogras, também, reconhecem que não possuem informações suficientemente atualizadas e, buscam encontrá-las na perspectiva de prolongar o aleitamento materno. Dessa forma, podem contribuir na implementação dos cuidados necessários à família em processo de amamentação. Logo, para que estes indivíduos possam promover, proteger e apoiar o aleitamento materno, faz-se necessário proporcionar espaços que possam envolvê-las e nos quais seja possível o debate de questões que permeiam a prática da amamentação. Assim, o apoio destas poderá ser um elemento facilitador para a manutenção da amamentação. ${ }^{9}$

Por fim, o companheiro não foi destacado por nenhuma das participantes na vivência da prática da amamentação. Acredita-se que o companheiro consiste em um importante aliado, tanto no exercício da maternidade quanto na lactação, podendo proporcionar auxílio valioso e total apoio à mulher nesse período. O pai pode influenciar positiva ou negativamente, em alguns casos, eles têm o potencial de estimular as mulheres a prosseguirem amamentando. Enquanto em outras situações, podem apresentar sentimentos de ansiedade, ciúme, rejeição, exclusão, dificuldades sexuais, muitas vezes, abandonando suas companheiras, especialmente, nas madrugadas em que ficam sozinhas amamentando. Tais atitudes, positivas ou negativas, envolvem, na maioria das vezes, a compreensão da amamentação pelo pai, se o pai percebe a importância da amamentação, ele pode mostrar-se como um agente incentivador, protetor e apoiador da amamentação. Porém, se este vislumbra a amamentação como uma prática negativa, que o excluí do cuidado de seu filho, ele pode apresentar-se pouco colaborativo, incomodado, inferior, deslocado e incompetente, acreditando que não possa participar desse ato, já que a amamentação é uma exclusividade da mãe. ${ }^{9}$

A inclusão paterna na saúde materno-infantil e a educação em saúde estão cada vez mais presentes, porém os profissionais de saúde não estão aptos para recebê-los nas consultas de pré-natal ou até mesmo nos centros obstétricos, pois durante a graduação, os temas abordados são principalmente sobre técnica, manejo e composição do leite, ficando os aspectos psicológicos e a inclusão paterna esquecida durante o ciclo grávidopuerperal. Dessa forma, ressalta-se a importância da aproximação entre academia e o serviço de saúde, a fim de contribuir para a melhoria do processo formativo e no desenvolvimento de competências necessárias à prática profissional. $^{8}$
A amamentaçáo na primeira hora de vida do recém-nascido é indicada desde que a mãe e seu filho estejam em boas condições. A separação do recém-nascido de sua mãe é um fator que dificulta a amamentação na primeira hora de vida e eleva as chances de desmame precoce, principalmente se foram administradas fórmulas lácteas, que poderão dificultar a amamentação. ${ }^{10}$

O recém-nascido atermo apresenta três Períodos de Transição do Recém-nascido ou de Transição Neonatal. O período inicial de transição neonatal ou período de reatividade ocorre nos primeiros 30 a 60 minutos de vida do recém-nascido. Este é o momento em que o bebê se apresenta alerta, explorador, e mostra o vigor necessário para o início da amamentação. Nesta fase mostra-se ativo, com reflexo forte de sucção e realiza contato olho a olho com sua mãe. Este é considerado o momento ótimo para interação mãebebê. O segundo período de transição neonatal chamase Período de Inatividade Relativa, que acontece a partir da segunda hora e se estende até a terceira hora de vida do bebê. Não é considerado o momento ideal para amamentação, já que neste período o recém-nascido mostra-se menos interessado aos estímulos externos e adormece de alguns segundos até algumas horas, não sendo recomendados estímulos sensoriais. O terceiro período de transição neonatal, ou o Segundo Período de Reatividade, tem duração de quatro a seis horas e iniciase após o despertar do primeiro sono do recém-nascido. Neste período o bebê pode e deve ser estimulado, dando continuidade à amamentação ou estimulá-lo para isso caso ainda não tenha iniciado. ${ }^{10}$

$\mathrm{O}$ aleitamento materno imediato, juntamente com o contato pele-a-pele entre a mulher e recém-nascido são fatores importantes para diminuição do sangramento em função da liberação de ocitocina endógena na mulher. $\mathrm{O}$ contato pele a pele auxilia na adaptação do recém-nascido à vida extrauterina. Mas revela que em seu estudo houve uma baixa taxa de amamentação no período de transição neonatal, especialmente, na primeira hora de vida, apenas $66,1 \%$ dos recém-nascidos foram colocados em contato pele a pele imediatamente após o nascimento, prática que deve ser realizada em partos vaginais e em cesarianas. E os dados mostraram que estímulo à amamentação não respeita os períodos de transição neonatal em que os bebês se encontram. ${ }^{10}$

Nos partos vaginais a taxa de episiorrafia teve índice bastante elevado, já que o uso de episiotomia não é indicado para todos os partos vaginais e pode acarretar riscos e complicações puerperais. Pesquisa realizada em São Paulo revelou que a ocorrência de lesão no períneo tem implicações na disposição da mulher para amamentar no pós-parto, em razão das limitações pelo desconforto e pela posição corporal. O parto e o período de pós-parto imediato são os períodos de maior vulnerabilidade tanto para mulher quanto para o recémnascido. ${ }^{10}$ 
A cesariana foi vista como fator que contribuiu para o adiamento do contato e da primeira mamada. Apesar de esta constatação não ser passível de generalização devido ao número de sujeitos deste estudo, outras pesquisas, nacionais e internacionais, mostraram, de forma estatística, haver relação significativa entre contato pele a pele e o parto cesáreo, sendo essa relação inversamente proporcional. A cesariana é vista como um fator de risco na medida em que interfere na capacidade da mãe de se movimentar, pela situação e posicionamento decorrentes do procedimento cirúrgico e pelo efeito da anestesia, que por sua vez, pode interferir na condição de alerta da mãe e do bebê. ${ }^{10}$

Os achados reforçam a importância de as maternidades capacitarem seus profissionais a fim de que possam auxiliar as mulheres e seus familiares nesse sentido, para que se evitem fissuras (traumas mamilares) e para que haja uma boa evolução do aleitamento materno. ${ }^{10}$

\section{Atuação da enfermagem junto as dificuldades das puérperas ao aleitamento materno}

Amamentar não é um processo simples: envolve questões sociais, biológicas, psicológicas e culturais. Inicialmente, devem-se respeitar os desejos e decisões maternas, porém, cabe aos enfermeiros orientá-las visando garantir a melhor alimentação para o recémnascido. Sendo assim, o manejo clínico da amamentação deve ser iniciado ainda no pré-natal, período em que a mulher já vai compreendendo a fisiologia da lactação, os benefícios para si e para o bebê durante a amamentação, dos intervalos entre as mamadas, dos sinais de hipoglicemia, o que lhe permite chegar à maternidade com esses conhecimentos. Se a orientação correta começar precocemente, as intervenções tenderão a diminuir quando a amamentação tiver sido iniciada. ${ }^{11,12}$

Algumas pesquisas demonstram que o pré-natal é o momento mais oportuno para o desenvolvimento de ações educativas direcionadas para a mulher, visando à promoção do aleitamento materno e ao sucesso dessa prática. A escolha da mulher de amamentar ocorre, na maioria das vezes, ainda durante a gestação. Nesse sentido, as orientações e o incentivo para a amamentação durante a assistência pré-natal contribuem de forma positiva para a decisão da mãe pelo início e duração do aleitamento materno. Uma assistência pré-natal com início precoce, com alto número de consultas realizadas e permeada de orientações referentes à amamentação traz influências positivas sobre a duração do aleitamento materno, principalmente o aleitamento materno exclusivo. ${ }^{13}$

Diante disso, o Ministério da Saúde preconiza que a primeira consulta de pré-natal seja realizada até 120 dias de gestacão e que seiam realizadas no mínimo, seis consultas, sendo uma no primeiro trimestre gestacional, duas no segundo trimestre, três no terceiro trimestre e uma, até 42 dias do puerpério. ${ }^{13}$ Para tanto Garcia, et al informa que a realização de algumas atividades no pré-natal são competências do profissional enfermeiro e possuem amparo legal no que se refere ao acompanhamento do pré-natal de baixo risco, de acordo com a Lei do Exercício Profissional da Enfermagem no Brasil. Além disso, a Lei 7.498 de 25 de julho de 1986 regulamenta a consulta de enfermagem e descreve que cabe ao enfermeiro a realização da mesma e a prescrição da assistência de enfermagem; bem como a prescrição de medicamentos, desde que estabelecidos em Programas de Saúde Pública e em rotina aprovada pela instituição de saúde e ainda, ofertar assistência de enfermagem à gestante, parturiente e puérpera. ${ }^{14}$

Dessa forma, o enfermeiro precisa saberidentificar, ao longo do pré-natal, os conhecimentos, a experiência prática, as crenças e as vivências social e familiar da gestante com o intuito de promover educação em saúde para o aleitamento materno, assim como, garantir vigilância e efetividade durante a assistência à nutriz no pós-parto. ${ }^{15}$ Costa, et al prossegue afirmando que os enfermeiros são profissionais de suma importância para a promoção do apoio ao aleitamento materno junto à nutriz, propiciando o seu acolhimento e a escuta ativa, para que ela seja a responsável pelo cuidado, destarte favorecendo a prática da amamentação. ${ }^{16}$

O manejo clínico da amamentação quando realizado por profissional habilitado, visa estimular o aleitamento materno ao demonstrar às mulheres práticas corretas, observando e corrigindo alguns problemas comuns como erro de pega e de sucção, insegurança materna, como também prevenindo agravos como infecções mamilares e mastites, que poderiam interferir no estabelecimento de uma amamentação saudável e favorecer o desmame precoce. Nesse sentido, o enfermeiro deve contribuir para o fortalecimento de sua prática profissional no manejo clínico da amamentação, pois a formação da enfermagem está entrelaçada com a perspectiva do processo de cuidar, intimamente ligada com o cuidado em saúde que perpassa pelas estratégias de orientação no manejo clínico da amamentação, a qual promove o aleitamento exclusivo e complementar, respaldado pelas Políticas Públicas na área do aleitamento materno. ${ }^{16}$

Guimarães, et al cita que apesar de os benefícios do aleitamento materno já estarem amplamente descritos na literatura e abranger as crianças, as mulheres e as famílias, percebe-se que a maioria das mulheres inicia o aleitamento materno, mas o interrompe precocemente. Estudos demonstram que o desmame precoce é um evento de ocorrência mundial e estima-se que apenas $34,8 \%$ das crianças recebam leite materno exclusivamente durante os primeiros seis meses de vida. No Brasil, a prevalência do aleitamento 
materno exclusivo em menores de seis meses foi de $41 \%$ no conjunto das capitais brasileiras e Distrito Federal. ${ }^{17}$ Costa, et al sinaliza que período mais difícil para o aleitamento materno ocorre nas primeiras duas semanas na residência da mulher, pois a inexperiência da puérpera diante de uma situação nova, diferente de toda sua vivência, tende a deixá-la assustada levando ao sentimento de impotência que pode perdurar. Com isso, alguns problemas relacionados com a dificuldade inicial de amamentar, ou o desconhecimento a respeito da prática da amamentação, podem ocasionar complicações e levar ao desmame precoce. ${ }^{16}$

Posto isso, os problemas maternos mais recorrentes relacionados ao aleitamento que são pega incorreta, mastite, ingurgitamento, ausência de orientação, baixa produção, fissura, infecção cruzada, bico invertido e resistência quanto ao ato de amamentar ${ }^{15}$ Trojanh, et al notabiliza as barreiras que interferem negativamente na manutenção da lactação, sendo a prematuridade também um dos fatores que inviabilizam o estabelecimento do aleitamento materno ou acarretam desmame precoce. Evidências indicam que no início do aleitamento materno o maior índice de dificuldades está relacionado às respostas do recém-nascido pré-termo, como a imaturidade dos reflexos orais. Em relação às dificuldades enfrentadas pelas mães, destacam a preocupação de o leite materno não ser suficiente para alimentar o recém-nascido e a dificuldade para realizar a ordenha mamária. ${ }^{18}$

O mito do "leite fraco" ainda existe para muitas mulheres. Essa ideia já é aceita culturalmente pelas pessoas como uma forma de minorar o insucesso e o pesar da mãe durante a lactação, uma vez que a não produção de leites adequados que seriam capazes de satisfazer as necessidades nutricionais da criança faz com que se sintam duvidosas e inseguras, fazendoas procurar alternativas para suprir as necessidades alimentares do bebê. ${ }^{19}$

Desse modo, vale destacar que os incrementos alimentícios antes dos seis meses de idade podem provocar, além de outras complicações para os recémnascidos, diarreias em grande frequência, internações hospitalares por complicações respiratórias, aumento do número de desnutridos e baixo peso. Os riscos de esses alimentos serem mal diluídos e apresentarem valores nutricionais ínferos aos do leite materno são bem comuns. ${ }^{19}$

As facilidades e dificuldades permearam o universo consensual das mães-nutrizes. Dentre as facilidades encontradas, a sensação de bem-estar e o prazer por estar contribuindo para a saúde de seus filhos foram as principais. Quanto as dificuldades, as mais relatadas foram: a amamentação requer tempo, pega e posicionamento inadequados, problemas mamilares e os mitos e tabus relacionados ao leite materno. ${ }^{20}$ Sobretudo Vieira, et al reitera que o sucesso em uma lactação adequada depende de uma interação entre mãe e filho, família, profissional e sociedade, sendo importante que todos estejam preparados para dar apoio/suporte à mãe no manejo da lactação/amamentação. ${ }^{21}$

Portando, o profissional de saúde deve ser um incentivador e um facilitador da prática da amamentação valendo-se de informações adequadas e acessíveis ao entendimento e ao conhecimento da mulher nutriz. Cabe, ao profissional de saúde possuir conhecimento, atitudes adequadas e habilidades específicas de reconhecimento das principais dificuldades que a puérpera encontra, podendo para tanto realizar até mesmo uma educação teórico-prática coletiva ou individualizada. E por fim, é necessário que os profissionais de saúde observem alguns princípios básicos, como a escuta ativa, na qual o profissional deve levar em conta toda informação que a mulher fornece com linguagem acolhedora, com expressão não verbal de respeito e paciência, inibindo eventuais barreiras entre profissional-mulher; atenção e empatia frente aos sentimentos da mulher sem qualquer julgamento prévio, além de tomada de decisão para promover a sua autonomia. Agindo desse modo, o profissional de saúde tem maior possibilidade de garantir o sucesso do aleitamento materno, e para isso acontecer, perpassa pelo apoio emocional não esquecendo que diálogo, corresponsabilidade, acolhimento e criação de vínculo de confiança favorecerão, sem dúvida, o manejo clínico da amamentação e a valorização dessa prática. ${ }^{16}$

\section{A autoeficácia materna na amamentação e a importância do leite materno}

O colostro é o primeiro leite com o qual o recémnascido ( $\mathrm{RN}$ ) tem contato, quando realiza a sucção nas mamas da nutriz. É um líquido amarelado, viscoso, que se encontra nos alvéolos das mamas desde o último trimestre da gestação, até os primeiros dias do pós-parto. Em geral, a "descida do leite" acontece até 30 horas após o parto. É um leite excretado em pequena quantidade, mas suficiente para alimentar e suprir as carências do neonato. Apresenta-se rico em proteína, contém sódio, potássio, cloro e vitaminas lipossolúveis como $\mathrm{E}, \mathrm{A}, \mathrm{K}$, além de ser descrito como uma vacina natural rica em anticorpos de transferência vertical. O colostro possui uma abundância de citocinas, todas úteis nesse período da vida, componentes bioativos do leite e essenciais para o desenvolvimento neonatal. ${ }^{22}$

Estudos de grande alcance, tais como da OMS e do Ministério da Saúde, que relatam a relevância do primeiro leite, transmitindo para a comunidade o quão primordial é a utilização do colostro para a saúde da criança, nas primeiras horas e dias de vida do $\mathrm{RN}$, sobretudo, no que diz respeito à diminuição da mortalidade neonatal. Muitos são os mitos e as crenças que circundam o colostro, dentre eles, a crença do 
leite fraco, o mito do leite insuficiente, do pouco leite e de que o bebê não quis pegar o peito. Essas crenças e mitos estão enraizados no senso comum entre os indivíduos. ${ }^{22}$

Ainda há uma parcela significativa das primíparas que possuem algum tipo de mito ou crença sobre a amamentação com relação ao leite ser considerado fraco e a sua produção não ser suficiente para amamentar a criança. Segundo algumas puérperas referenciou a falta de informação como um aspecto que é uma das causas pelas quais ela e outras nutrizes não conhecem os componentes do primeiro leite. Portanto, é necessário que a equipe multiprofissional realize educação em saúde para as pessoas envolvidas no processo de amamentação, pois será por meio desta ação que as puérperas irão se embasar para realizar suas ações, tendo motivos para oferecer o colostro aos seus filhos e prosseguir aleitando exclusivamente até o sexto mês de vida e, complementado com outros alimentos, por dois anos ou mais. ${ }^{23}$

É importante ressaltar sobre o cheiro do leite, diante disto Leite, et al salienta que o estímulo causado pelo cheiro do leite apresenta vantagens para o recémnascido quanto à maturação e evolução da sucção. Além disso, há considerações sobre a estimulação sensorial (cheiro, toque, olhar) do recém-nato que acontece durante o contato íntimo da amamentação, a qual promove o envolvimento entre a mulher/mãe e seu filho, e a formação do vínculo afetivo. O cheiro do leite foi representado por odores de alguns alimentos ou considerado desagradável, porém predominou o sentimento de aceitação desse cheiro em função dos benefícios do leite à saúde do filho. No sentido de minimizar esses odores de características variadas que levam ao incômodo, as lactantes cuidam da higiene corpórea com mais frequência, para que o seu aroma seja representado pelo cheiro do próprio corpo. ${ }^{24}$

Para algumas das nutrizes um ponto muito importante é o apoio paterno à amamentação que também foi enfatizado dentre as representações sociais das mulheres, mesmo quando o cheiro do leite foi considerado inconveniente. Isso consolida o vínculo entre mãe, pai e bebê, e encoraja a mulher a manter, por mais tempo, o aleitamento, pois a aprovação do pai a essa prática é primordial para o sucesso. $\mathrm{O}$ aleitamento materno é amplamente estudado, mas informações sobre o cheiro do leite materno devem ser mais investigadas. A compreensão desta particularidade inserida no contexto da amamentação é essencial. Portanto, é necessária a formulação de novas estratégias de atenção em saúde que abordem uma visão ampliada da amamentação, incluindo aspectos relacionados ao odor do leite materno. Isso porque conhecer essas questões olfatórias pode contribuir para o planejamento de ações em saúde e de enfermagem mais condizentes com as necessidades das mulheres-mães que vivenciam a amamentação, com o objetivo de amenizar o desconforto causado pelos odores do leite e auxiliar na manutenção da prática de aleitar, do vínculo entre mãe e filho, dos relacionamentos interpessoais e no bem-estar da mulher. ${ }^{24}$

A amamentação de prematuros, bem como a autoeficácia materna em amamentar são fatores que estão associadas e tornam-se essenciais para a detecção do problema e subsídio para possíveis formulações de estratégias que possam auxiliar a promoção e manutenção do aleitamento materno, especialmente em prematuros. Diante desse enfoque, acredita-se que o sucesso da amamentação depende de medidas favoráveis que possam influenciar os envolvidos de forma satisfatória, sempre levando em consideração os fatores que estão diretamente relacionados às mães e aos situacionais das condições de vida. ${ }^{25}$

Um dado preocupante, mais da metade das mães revelarem não ter recebido informações sobre aleitamento materno durante o pré-natal. Esse fator prejudica substancialmente a adesão à sua prática, visto que o pré-natal é uma assistência prestada à saúde materna e neonatal. Entretanto as mães mostraram-se com alta eficácia em amamentar seus filhos prematuros, reafirmando enfrentar a amamentação da mesma forma que superam os desafios cotidianos. Contanto, na observação da técnica da mamada, esta se apresentou ineficaz. Diante dessa informação, cabe ressaltar que essa realidade pode estar atrelada à fragilidade da assistência, à inconsistência da equipe de saúde, a pouca interação ou falta de adequação de conhecimento prévio da exata forma de aconselhar, bem como pode ser um alerta para a reestruturação na qualidade das consultas de pré-natal..$^{25}$

O puerpério é um período, especialmente, oportuno para assistência à mãe, filho e família e, que qualquer fragilidade que afete um desses três grupos alvo, representa uma ameaça à saúde infantil, uma vez que é fundamental o papel das mães em relação aos cuidados com as crianças e que o desenvolvimento dessas é, diretamente, influenciado pelas condições das famílias nas quais vivem. O puerpério, tempo de seis a oito semanas após o parto, didaticamente, pode ser dividido em três períodos, sendo: imediato $\left(1^{\circ}\right.$ ao $10^{\circ}$ dia), tardio $\left(11^{\circ}\right.$ ao $45^{\circ}$ dia) e remoto (a partir do $45^{\circ}$ dia). No puerpério ocorrem modificações internas e externas, configurando-se como um período carregado de transformações psíquicas, onde a mulher continua a precisar de cuidado e proteção. Assim, a mulher, durante o período puerperal, precisa ser atendida em sua totalidade, por meio de uma visão integral que considere o contexto sociocultural e familiar. ${ }^{26}$

Os profissionais de saúde devem estar atentos e disponíveis para perceber e atender as reais necessidades apresentadas por cada mulher, qualificando o cuidado dispensado. Quando as intervenções de saúde realizadas no puerpério são dirigidas atreladamente à 
mulher, criança e família acabam por promover a saúde e bem-estar infantil, uma vez que a presença da mãe é fundamental para a criança, tal como a convivência com pais que se relacionam bem, num ambiente familiar saudável. Assim, os determinantes do processo saúde-doença comuns, nesse período, bem como as ações de saúde ou ausência delas, repercutem direta e indiretamente na saúde das crianças. Sendo as crianças seres mais vulneráveis, são elas as mais beneficiadas por um contexto saudável de vida em família. ${ }^{26}$

Algumas dificuldades encontradas no período do puerpério em mães primíparas segundo Silva, et al são as falas de que o ambiente interfere o momento da amamentação e que a amamentação ocupa muito tempo dificultando o serviço de casa. Nota-se em outro ponto que são as mães que acreditam em mitos e crenças, por exemplo, de que a amamentação faz os seios caírem e que o leite materno, por si só, não sustenta a criança. Entre as dificuldades citam-se também as fissuras da mama que ocorrem com o tempo da amamentação ineficaz e a mastite puerperal, (que é um processo inflamatório que deixa as mamas endurecidas). Ressaltase que, as dificuldades apresentadas durante o processo de amamentação relacionaram-se à posição do bebê, à pega incorreta, além da falta de informação sobre a fisiologia do bebê e do mamilo invertido. ${ }^{23}$

As expectativas ou crenças na autoeficácia, construídas pelas mulheres, podem influenciar $\mathrm{o}$ julgamento sobre sua habilidade para iniciar, vencer as dificuldades e continuar a amamentação. Essas estão relacionadas com experiência pessoal, observação de modelos (entendida como experiência vicária com o aleitamento), persuasão verbal de pessoas influentes em prol da amamentação, além de fatores como dor, ansiedade e fadiga, que podem interferir na confiança da mulher em amamentar e consequentemente na prevalência do aleitamento materno exclusivo. ${ }^{27} \mathrm{Silva}$, et al sugere que seria válido que a equipe multiprofissional fosse mais atuante nos problemas encontrados durante as orientações realizadas buscando, em conjunto com a mãe, solucionar esses empecilhos levando em consideração sua situação financeira, seu grau de esclarecimento e seu estilo do de vida e garantindo, assim, a manutenção do aleitamento materno exclusivo até o sexto mês de vida do bebê para promover maior qualidade na saúde física e emocional do binômio mãe/ filho. ${ }^{23}$

O estudo de metanálise constatou a eficácia das intervenções educativas iniciadas no pré-natal na prevalência do aleitamento materno exclusivo aos 6 meses. A autoeficácia materna é reconhecida como um preditor para a amamentação capaz de ser modificado por meio de intervenções educativas, as quais podem minimizar as influências negativas das crenças na autoeficácia materna para amamentação. Pelo exposto, justifica-se a realização de intervenções no pré-natal com ferramentas educativas que permitam ao educador em saúde uma abordagem que confira à mulher confiança em suas habilidades para amamentar. ${ }^{27}$

\section{Influências das redes sociais acerca do conhecimento das puérperas}

Para Rocha et al O Fundo das Nações Unidas para a Infância e a Organização Mundial de Saúde, as taxas de aleitamento materno exclusivo ainda estão muito abaixo das esperadas no mundo. A realização de ações educativas no decorrer do ciclo gestacional e pós-parto é necessária, e é no pré-natal que a mulher deve ser preparada para obter sucesso na amamentação. Mesmo aquelas que afirmaram ter recebido orientação, este conhecimento é limitado, constatando que existe um conhecimento superficial relativo à prática e resultados benéficos do aleitamento para ambos. ${ }^{28}$

Estudos apontaram que o parto por cesariana colabora para o afastamento da mãe e do bebê, e é reconhecido pela Organização Mundial da Saúde (OMS) como uma condição negativa para a execução da amamentação ao nascimento. Sendo assim, uma revisão sistemática que buscou verificar os fatores associados ao aleitamento materno na primeira hora de vida, também evidenciou que o parto cesáreo foi considerado o fator de risco mais consistente para a não amamentação na primeira hora de vida. De modo geral, observou-se que o sucesso da prática do aleitamento materno depende do preparo das mulheres em seu ciclo-gravídico puerperal, principalmente durante o pré-natal. ${ }^{28}$

O enfermeiro deve criar um vínculo de confiança com a mãe permitindo, esclarecer dúvidas relacionadas ao aleitamento materno, ao manejo, à prevenção de complicações e dificuldades para reforçar a importância da amamentação exclusiva nos primeiros seis meses de vida, tanto para a saúde da mãe quanto a do bebê. ${ }^{28}$

A prática da amamentação é diretamente influenciada por diferentes aspectos biológicos e pelas condições sociais da nutriz, como idade, escolaridade, condições de trabalho e vivência em sociedade, sendo esta última representada pelas redes de apoio social que a circunda. $O$ contexto sociocultural onde a mulher está inserida e a ansiedade com relação à amamentação resulta em prática complexa, a qual é influenciada pela vivência da nutriz em sociedade, permeada de mitos, crenças e valores repassados durante as gerações. $\mathrm{O}$ aleitamento materno proporciona benefícios de saúde para mulheres e seus filhos, porém a prevalência da amamentação tem se mostrado mais baixa em mães adolescentes, em comparação com as mães idade mais avançadas. As mães adolescentes constituem um grupo de risco para a continuidade do aleitamento materno, assim considerase relevante o apoio familiar e social, para que estas jovens mães se sintam estimuladas e consigam dar 
continuidade ao processo de amamentar. ${ }^{29}$

Como principais elementos de apoio a amamentação, os familiares que durante esta fase da vida tendem a estarem mais presentes no cotidiano das jovens mães auxiliando no cuidado com o bebê e atividades domésticas. A família como elemento da Rede Social de Apoio Primária, possui importância fundamental no cuidado aos seus membros, considerada o primeiro espaço de socialização do indivíduo, onde ele desenvolve os primeiros conceitos do meio que o cerca, bem como sua identidade social. As nutrizes que relataram maior vínculo com a rede secundária apresentaram maior conhecimento sobre o tema aleitamento materno e consequentemente amamentaram por mais tempo, pois as mesmas citaram os profissionais de saúde como o segundo grupo de maior influência no apoio e incentivo ao aleitamento materno. Estudos sobre amamentação trazem a importância da rede secundária para a promoção do aleitamento materno. ${ }^{29}$

O profissional de saúde deve ser capaz de desenvolver laços estreitos com a nutriz, para que possa desempenhar um papel de auxílio e incentivo à promoção da saúde da nova mãe e de seu bebê, especialmente com relação ao aleitamento materno. Para tanto a atuação deste profissional pode ocorrer em diferentes etapas, desde o período pré-gestacional ao puerpério, quando este é efetivo, a gestante adolescente sente-se mais segura e qualificada para realizar o cuidado com o filho de forma mais adequada. O papel da educação em saúde para a promoção do aleitamento materno mostra-se fundamental, sendo assim o mesmo deve conhecer a realidade de vida da nutriz, e após esta etapa estabelecer um plano de ações para o incentivo do aleitamento materno que esteja de acordo com a realidade encontrada. ${ }^{29}$

Conforme relatado no discurso das gestantes, notase a forte influência da internet como um meio de busca de informações acerca do tema aleitamento materno. Percebem-se também as opiniões das demais mulheres que já passaram pela experiência da amamentação e que formam a rede de apoio das gestantes como fontes de informação e ponto de referência sobre o assunto para estas. Outra questão diz respeito ao fato de que pela internet as mulheres adquirem facilmente diversas informações, atuando como um importante meio para a promoção da saúde e do aleitamento materno. A internet atualmente é uma das principais fontes de informação em saúde, no entanto, é preciso atentar para o consumo de informações verídicas à população, evitando assim riscos e possíveis danos aos usuários que consultam informações sobre saúde por esse meio.

A partir dessa discussão acerca da utilização da mídia digital como fonte de informações sobre o aleitamento materno por parte das gestantes, e tendo em vista a era tecnológica que a sociedade vive, cabe aos profissionais de saúde estarem atentos às informações captadas por essas mulheres, a fim de detectar o acesso a informações errôneas e equivocadas sobre o assunto.

Além disso, é preciso disponibilizar fontes seguras de conhecimento a essa população, garantindo assistência pré-natal de qualidade, que promova a prática do aleitamento materno. ${ }^{19}$

\section{Considerações finais}

Diante o proposto estudo obtivemos pontos positivos e negativos. A começar pelos negativos, é nítida a falta de informação dada à gestante através da enfermagem, sobretudo no pré-natal que seria o momento mais propício para tal feito, já que é nesse momento que a mulher decide se vai amamentar ou não. A alta demanda de pacientes e sobrecarga de trabalho prejudica a enfermagem de prestar um serviço de qualidade como também a dar as orientações necessárias a essas gestantes, causando assim um déficit no conhecimento das nutrizes que pode levar a não aceitação da amamentação, crenças errôneas e efetuar falhas na hora da amamentação como a pega incorreta. Muitos são os fatores que levam a abdicação ou interrupção da amamentação, vale ressaltar os mais recorrentes que são a alteração do seu corpo (em geral o mito da ptose mamária), dores e complicação no período do ciclo gravídico-puerperal, mulheres sem uma rede social de apoio ativa e que precisam voltar ao trabalho, crença na hipogalactia, gravidez indesejada, mães adolescentes e o parto prematuro.

Apesar de todas essas limitações, atentamos para os pontos positivos como as mães que ultrapassam suas barreiras e se esforçam para ofertar ao seu filho o leite materno, mesmo diante de mastites, ingurgitamento mamário, rachaduras das mamas e dores acometidas pelo parto, entre outros. Contemplamos também que uma rede de apoio social ativa, principalmente o cônjuge e familiares próximos à nutriz agrega força para enfrentar as dificuldades impostas na amamentação.

Em virtude dos fatos mencionados constatou-se que a enfermagem é de grande importância nas ações educativas e no incentivo e apoio as gestantes, bem como, sua atuação nas dificuldades encontradas. A equipe de enfermagem que consegue exercer de forma efetiva seu papel obtêm resultados positivos com a nutriz, criando um vínculo de confiança para que ela possa tirar suas dúvidas, medos, inseguranças e obter conhecimento quanto a amamentação materna exclusiva e complementado e realizá-la de forma definitiva

\section{Referências}

1. OPAS. Brasil. Aleitamento materno nos primeiros anos de vida salvaria mais de 820 mil crianças menores de cinco anos em todo o mundo. Disponível em: $<$ https://www.paho.org/bra/index.php?option=com_content \&view=article\&id=5729:aleitamento-materno-nos-primeiros-anos-de-vida- 
salvaria-mais-de-820-mil-criancas-menores-de-cinco-anos-em-todo-o-mundo\&Itemid=820. $>$ Acesso em: 07/03/2020.

2. Costa LHP, Silva MC. Importância do aleitamento materno exclusivo. 2018. Trabalho de conclusão de curso - Faculdade de ciências da educação e saúde curso de nutrição, Centro Universitário de Brasília- UniCEUB, Brasília, 2018. Disponível em: <https://repositorio.uniceub.br/jspui/ bitstream/prefix/13294/1/21551030.pdf>. Acesso em: 07/03/2020.

3. Lakatos EM, Marconi MA. Metodologia científica. 4. reimpr. São Paulo: Atlas, 2010

4. Souza FLP. et al. Sentimentos e significados: HIV na impossibilidade de amamentar. Rev. enferm. UFPE on line ; 13:e241854, 2019. Disponível em: $\quad<$ https://periodicos.ufpe.br/revistas/revistaenfermagem/article/ view/241854/33511>. Acesso em: 06/04/2020.

5. Costa AMS. et al. Cuidado de enfermagem às puérperas soropositivas para o HIV diante da impossibilidade de amamentação natural. Rev. Pesqui. (Univ. Fed. Estado Rio J., Online); 7(2): 2310-2322, abr.-jun. 2015. Disponível em: < http://www.seer.unirio.br/index.php/cuidadofundamental/ article/view/3841/pdf 1539>. Acesso em: 06/04/2020.

6. Lima CN, Rêgo HCLJ, Moraes LP. Aleitamento materno: a visão de puérperas soropositivas para hiv e htlv quanto a não amamentação. Nursing (Säo Paulo); 22(248): 2583-2586, jan.2019. Disponível em: <http://www. revistanursing.com.br/revistas/248/pg35.pdf>. Acesso em: 06/04/2020.

7. Móta JLS, et al. Sala de apoio à amamentação na universidade. Rev enferm UFPE on line., Recife, abr., 2019; 13(4):1179-82, Disponível em: $\quad<$ https://periodicos.ufpe.br/revistas/revistaenfermagem/article/ view/238617/31860>. Acesso em: 06/04/2020

8. Thuler ACMC, Wall ML, Souza MAR. Caracterização das mulheres no ciclo gravídico-puerperal e o incentivo à amamentação precoce. Rev. enferm. UERJ; Rio de Janeiro, jan.-dez. 2018; 26: e16936. Disponível em: <https://www.e-publicacoes.uerj.br/index.php/enfermagemuerj/article/ view/16936/26121>. Acesso em: 06/04/2020.

9. Prates LA, Schmalfuss JM, Lipinksi JM. Rede de apoio social de puérperas na prática da amamentação. Esc. Anna Nery Rev. Enferm; Rio de Janeiro, Abr-Jun/2015;19(2): 310-315, Disponível em: <https://www.scielo. $\mathrm{br} /$ scielo.php?script $=$ sci_arttext\&pid $=\mathrm{S} 1414-81452015000200310>$. Acesso em: 06/04/2020.

10. Teles JM, et al. Amamentação no período de transição neonatal em Hospital Amigo da Criança. Rev. eletrônica enferm., jan./ma. 2015.; 17(1): 94-99. Disponível em: <http://docs.bvsalud.org/biblioref/2017/03/832413/ v17n1a11.pdf>. Acesso em: 06/04/2020.

11. D'artibale EF, Bercini LO. A prática do quarto passo da iniciativa hospital amigo da criança. Esc. Anna Nery Rev. Enferm; Rio de Janeiro, Abr-Jun/2014; 18(2): 356-364. Disponível em: < https:/www.scielo.br/ scielo.php?script $=$ sci_arttext\&pid $=$ S1414-81452014000200356 $>$. Acesso em: 06/04/2020

12. Azevedo ARR, et al. O manejo clínico da amamentação: saberes dos enfermeiros. Esc. Anna Nery Rev. Enferm; Rio de janeiro, jul.-set. 2015; 19(3): 439-445. Disponível em: <https://www.scielo.br/scielo. php? script $=$ sci arttext\&pid $=$ S1414-81452015000300439>. Acesso em: 06/04/2020.

13. Silva AM, et al. Aleitamento materno exclusivo: empecilhos apresentados por primíparas. Rev. enferm. UFPE on line; Recife, dez. 2018; 12(12): 3205-3211. Disponível em: <https://periodicos.ufpe.br/revistas/ revistaenfermagem/article/view/236599/30770>. Acesso em: 06/04/2020

14. Maeda TC, Parreira BDM, Silva SR, Oliveira ACD. Importância atribuída por puérperas às atividades desenvolvidas no pré-natal. Rev. enferm. atenção saúde, jul-dez. 2014; 3(2): 6-18. Disponível em: <http:// seer.uftm.edu.br/revistaeletronica/index.php/enfer/article/view/1016/879>. Acesso em: 06/04/2020.

15. Garcia ESGF, et al. As ações de enfermagem no cuidado à gestante: um desafio à atenção primária de saúde. Rev. pesqui. cuid. fundam. (Online) jul.-set. 2018; 10(3): 863-870. Disponível em: <http://www.seer.unirio.br/ index.php/cuidadofundamental/article/viewFile/6255/pdf 1>. Acesso em: 06/04/2020

16. Fassarella BPA, et al. Percepção da equipe de enfermagem frente ao aleitamento materno: do conhecimento à implementação. Nursing (Säo Paulo) dez.2018; 21(247): 2489-2493. Disponível em: <http://www. revistanursing.com.br/revistas/247/pg43.pdf>. Acesso em: 06/04/2020.

17. Costa EFG, et al. A atuação do enfermeiro no manejo clínico da amamentação: estratégias para o aleitamento materno. Rev. Pesqui. (Univ. Fed. Estado Rio J., Online) jan.-mar. 2018; 10(1): 217-223. Disponível em: $\quad<$ http://www.seer.unirio.br/index.php/cuidadofundamental/article view/5953/pdf_1>. Acesso em: 06/04/2020.

18. Guimarães CMS, et al. A autoeficácia na amamentação e a prática profissional do enfermeiro. Rev. enferm. UFPE on line; Recife, abr. 2018; 12(4): 1085-1090. Disponível em: <https://periodicos.ufpe.br/revistas/ revistaenfermagem/article/view/230736/28684>. Acesso em: 06/04/2020.

19. Trojahn TC, et al. Cuidado de enfermagem às mães de recém-nascidos pré-termo para manutenção da lactação: estudo fenomenológico. REME rev. min. enferm; 2018;22:e-1105. Disponível em: <https://cdn.publisher.gn1. link/reme.org.br/pdf/e1105.pdf>. Acesso em: 06/04/2020.

20. Silva EC, et al. Puerpério e assistência de enfermagem: percepção das mulheres. Rev. enferm. UFPE on line; Recife, jul.2017;11(supl.7): 2826-2833. Disponível em: <https://periodicos.ufpe.br/revistas/revistaenfermagem/ article/view/11043/19180>. Acesso em: 06/04/2020.

21. Teixeira MA. et al. Cuidar em enfermagem às famílias que vivenciam a amamentação. Rev. enferm. UFPE on line; Recife, ago.2017;11(supl.8): 3190-3197. Disponível em: < https://periodicos.ufpe.br/revistas/ revistaenfermagem/article/view/110183/22063>. Acesso em: 06/04/2020.

22. Vieira GM, et al. Protocolo de enfermagem para assistência à mulher em processo de lactação. Rev. Pesqui. (Univ. Fed. Estado Rio J., Online) out.-dez. 2017; 9(4): 1040-1047. Disponível em: <http://www.seer.unirio. br/index.php/cuidadofundamental/article/view/5768/pdf_1>. Acesso em: 06/04/2020.

23. Santos RPB, et al. Importância do colostro para a saúde do recémnascido: percepção das puérperas. Rev. enferm. UFPE on line; Recife, set.2017; 11(supl.9): 3516-3522. Disponível em: <https://periodicos.ufpe. $\mathrm{br} /$ revistas/revistaenfermagem/article/view/234481/27672>. Acesso em: 06/04/2020.

24. Silva DD, et al. Promoção do aleitamento materno no pré-natal: discurso das gestantes e dos profissionais de saúde. REME rev. min. Enferm, 2018; 22: e-1103. Disponível em: <https://cdn.publisher.gn1.link/reme.org. br/pdf/e1103.pdf>. Acesso em: 06/04/2020.

25. Leite GO, et al. Representações sociais de mulheres sobre o cheiro do leite materno. Esc. Anna Nery Rev. Enferm; Rio de Janeiro, , 2016; 20(4): e20160090. Disponível em: <https://www.scielo.br/scielo.php?script=sci arttext\&pid $=$ S1414-81452016000400208>. Acesso em: 06/04/2020.

26. Lopes AM, et al. Amamentação em prematuros: caracterização do binômio mãe-filho e autoeficácia materna. Rev. bras. promoç. saúde (Impr.); Fortaleza, mar. 2015; 28(1): $\neg 32-\neg 43$. Disponível em: < https://periodicos. unifor.br/RBPS/article/view/2965/pdf>. Acesso em: 06/04/2020.

27. Andrade RD, Santos JS, Maia MAC, Mello DF. Fatores relacionados à saúde da mulher no puerpério e repercussões na saúde da criança. Esc. Anna Nery Rev. Enferm; Rio de Janeiro, Jan-Mar/2015; 19(1): 181-186. Disponível em: < https://www.scielo.br/scielo.php?script=sci_arttext\&pid=S141481452015000100181>. Acesso em: 06/04/2020.

28. Javorski $\mathrm{M}$, et al. Efeitos de uma tecnologia educativa na autoeficácia para amamentar e na prática do aleitamento materno exclusivo. Rev. esc. enferm. USP, São Paulo, 2018; v. 52, e03329. Disponível em $<$ http://www.revenf.bvs.br/scielo.php?script=sci_arttext\&pid=S008062342018000100419>. Acesso em: 06/04/2020.

29. Rocha FNPS, et al. Caracterização do conhecimento das puérperas acerca do aleitamento materno. Rev. enferm. UFPE on line; Recife, set. 2018; 12(9): 2386-2392. Disponível em: <https://periodicos.ufpe.br/revistas/ revistaenfermagem/article/view/235911/29926>. Acesso em: 06/04/2020.

30. Mazza VA, et al. Influência das redes sociais de apoio para nutrizes adolescentes no processo de amamentação. Cogitare enferm; Curitiba, abr.jun. 2014; 19(2): 254-260. Disponível em: < http://www.revenf.bvs.br/ scielo.php?script $=$ sci_arttext\&pid=S1414-85362014000200007>. Acesso em: 06/04/2020 